\title{
When High Touch Meets Low Tech: Knowledge Management in a Small Enterprise
}

\author{
Gloria H. W. Liu \\ Department of Information Management \\ National Central University, Taiwan 320, R.O.C. \\ glorialiu@mgt.ncu.edu.tw \\ Eric T. G. Wang \\ Department of Information Management \\ School of Management \\ National Central University, Jhongi, Taiwan 320, R.O.C. \\ ewang@mgt.ncu.edu.tw
}

\begin{abstract}
In this article, we propose an analytical framework for investigating how control of knowledge and knowledge workers is achieved in a translation agency. The organizational size and an organizational logic of self-management were found to drive control mechanisms into a minimalist style of joint management. On the one hand, the translators managed themselves through (a) the buy-in of an open and sharing culture and a new psychological contract, (b) information from the appraisal results, and (c) conversation and communication with other experts. On the other hand, the managers manage by employing (a) a strategy centered on the dictionary and directory elements of an open and sharing culture, (b) minimalist interventions to induce and structure spontaneous communication, and (c) freelancers to complement expertise within organizational boundaries. Our analysis establishes a prototype for managing individualistic knowledge work in small organizations. Implications of these findings include a configurational approach to KM research, a shift from the concern of rent appropriation to that of rent sharing, and viewing organizations as the context covered with communication channels that craft, groom and enable communication, conversation and mutual learning.
\end{abstract}

Keywords: Knowledge Management, Knowledge Workers, Organizational Culture, Psychological Contract, Translation Industry 
When High Touch Meets Low Tech: Knowledge Management in a Small Enterprise/Liu \& Wang

\section{Introduction}

Knowledge of an organization plays a strategically important role in its ability to compete (Barney, 1991; Grant, 1996). However, knowledge resides in individuals. Having knowledgeable employees does not necessarily mean that an organization is competitive. If knowledge cannot be transferred and applied in the organizational context, how can it create an advantage? Compared with physical assets, due to the information asymmetry, knowledgeable human capital is also associated with serious problems of opportunism and voluntary turnover. Lyon (2005) reveals that employees with expertise knowledge might shape perceived value of their expertise in self-serving ways, even at the cost of organizations. The desirable properties of tacitness and inimitability of knowledge then pose a managerial dilemma. Accordingly, to untangle issues related to knowledge management, answers to the following questions concerning people and the structure are desperately sought (Storey and Quintas, 2001):

1. Who owns and controls knowledge and what the consequences will be?

2. How will knowledge workers be managed and rewarded?

3. How can people be motivated to share knowledge?

4. How can organizations gain access to individuals' tacit and implicit knowledge?

5. Will knowledge management $(\mathrm{KM})$ require new organizational structure and if so, what form should it take?

However, KM has come to be associated with large IT systems or formalized strategies in big organizations. There is a notable lack of $\mathrm{KM}$ research in small and medium-sized enterprises (McAdam and Reid, 2001; Hutchinson and Quintas, 2008). Many scholars suggest that small and medium-sized enterprises (SME) should be considered as a separate class from their bigger counterparts for distinctive features, such as ad hoc planning and heavy reliance upon external connections to achieve competitive advantage (Robinson, 1982; Ghobadian and Gallear, 1996; Hutchinson and Quintas, 2008). Parallels can be drawn between the development of KM and that of total quality management (TQM). In retrospect, principles of TQM were first developed in large private organizations and lately have been enriched with studies within all sizes and types of organizations (Ghobadian and Gallear, 1996). Big organizations have been actively embracing the concepts of $\mathrm{KM}$, and time is ripe for investigating KM practices within the SME sector. Many studies find that though not familiar with the vocabulary of KM, many SMEs are proactive in managing knowledge (Moffett and McAdam, 2006; Hutchinson and Quintas, 2008). However, application of unmodified $\mathrm{KM}$ practices developed in big organizations by SMEs may produce adverse results.

Therefore, drawn upon literatures of human resource management and organizational control, we develop an analytical framework to investigate how control of knowledge and knowledge workers is achieved in a translation agency. To encompass both the formal and social contexts of a translation agency, four pillars of control mechanisms are conceived, including organizational culture, organizational structure, appraisal system and IT infrastructure. Our analysis attempts to (1) investigate how control is achieved by each mechanism, and (2) identify the "organizational logic" that exerts a pull toward a consistent bundle of control mechanisms.

The remainder of the paper is organized as follows. Section 2 unpacks the concepts of knowledge and its management. We propose four control mechanisms to capture the organizational logic of our case study. Section 3 describes how the case is selected and data are collected and coded. Section 4 presents the empirical evidence concerning the four control mechanisms and the underlying organizational logic that drives the configuration of the mechanisms. This is followed by a discussion on the configuration 
and emergent issues in Section 5. Section 6 provides the implications of the findings and concludes the paper.

\section{Theoretical Base and Analytical Framework}

\section{Knowledge as Social Capital}

Most students of cognitive psychology have used the term knowing or knowledge to denote learning or acquisition of a repertoire of schema at the individual level with a focus on the application of organized or prior schema to understand new knowledge. Nevertheless, many empirical studies indicate that knowing and knowledge at or beyond the individual level is influenced by various contextual factors, such as patterns of connections between individuals (Weick and Roberts, 1993), characteristics of the task, or the cultural context (Gibson, 1999). To complement the simple view of individual cognition, our analysis is rooted in the conceptualization of knowledge as social capital.

Impacts and functions of social capital are highly visible for empirical evidence indicates that social capital leads to positive as well as negative results, including more job opportunities, better economic performance, disparity, exclusion or limited openness to new ideas (Granovetter, 1973; Fernandez et al., 2000; Glaeser et al., 2000; Baron et al., 2001). However, it is never easy to elaborate the exact content of social capital. Putnam (1993) equates social capital to networks, norms and trust that facilitate coordination and cooperation. Bourdieu and Wacquant (1992) refer it to the sum of actual and virtual resources embedded in a durable network. Coleman (1994) defines it by its function and suggests it is a variety of different entities within a social structure. Despite the failure to distinguish social capital, these definitions distill into two cores of social capital, namely the social structure and resources. First, the social structure in an organization subsumes both the impersonal structure and personal relations, corresponding respectively to the structural and relational dimensions suggested by Nahapiet and Goshal (1998). The structural dimension describes connections in terms of density, connectivity or hierarchy. It elucidates how people are clustered, but fails to explain why people with similar positions achieve differently, whereas the relational dimension describes personal relations established through a history of interactions (Granovetter, 1992). The relational dimension connotes such important concepts as trust, norms, obligations, expectations and identity that help activate deeply embedded resources and explain the differential achievements. Second, the "resources" refer to a variety of different entities, which according to Coleman (1994) is the by-product of interaction. No consensus emerges as to what these resources are. All we offer is the recognition that there are many kinds of resources within social capital.

Knowledge has long been appraised as a strategically important resource, capable of generating competitive advantage due to its tacitness and inimitableness (Barney, 1991; Wright et al., 1994) which in turn gives rise to its stickiness. Once knowledge is created, the cost of its consumption is near zero, whereas knowledge is inseparable from social structures and only benefits people within the network. Therefore, knowledge management inevitably involves retention and motivation of people as well as design or induction of the social structure where knowledge is available, embedded and emanates. Taken together the cognitive and the social capital aspects of knowledge, we define knowledge as a cognitive and institutional resource embedded in the impersonal structures and personal networks. In the following, we discuss characteristics of knowledge workers, which have critical implications for our case study.

\section{Knowledge Workers}

Knowledge workers work at an inter-organizational level since they tend to identify with like-minded professionals, and develop personal relationships that span organizational boundaries (Swart, 2007). These relationships comprise channels for them to obtain useful information about their 
When High Touch Meets Low Tech: Knowledge Management in a Small Enterprise/Liu \& Wang

expertise in the market. They also use this network to gauge and establish their credibility. Small organizations can sometimes benefit from these relationships outside the regular employment relationships. However, these relationships are not at the discretion of the organizations. Three issues related to the management of knowledge workers are identified: value appropriation, identity fragmentation and skill specificity (Swart, 2007).

First, pay is the most important aspect of the job (May et al., 2002). Knowledge workers usually feel a right to high rents. If not addressed well, they tend to sell their knowledge directly to other organizations or clients. Second, knowledge workers are located within a broader knowledge network. They draw their identification from their profession, the client, or the team where they are embedded. This presents a danger of fragmented identification and low commitment to the organization. Third, traditional organizations usually develop firm-specific skills to lock in their employees. However, knowledge workers would rather trade employment for employability. Their commitment to an organization is usually limited to the development of transferable skills. Effective management of cognitive resources at the individual level then has to address these three problems.

\section{Management as Control}

Braverman (1974) argues "control is... the central concept for all management systems." Some control mechanisms are instrumental and aim to achieve efficiency, whereas some are communicative and aim to align divergent interests. Inevitably, behavioral assumptions underlie all organizational control mechanisms. Barley and Kunda (1992) summarize that both discourses promise productivity and profitability but advocate different means for attaining control. The normative and social control mechanisms usually rely on social psychological processes and operate through socialization and internalization of value systems. However, the artificial quality of organizations, which is based on the effort-reward employment relationship, cannot merely rely on voluntary participation of their members. Organizations need control mechanisms based on formal authority to secure compliance. A holistic framework of control mechanisms within an organization has to incorporate both formal and social controls.

Four control mechanisms are particularly relevant to knowledge management. They are the organizational culture, the organizational structure, the appraisal system and the IT infrastructure. Among them, the organizational culture, the organizational structure and the IT infrastructure respectively constitute the symbolic, bureaucratic and material contexts of an organization where knowledge is embedded. The appraisal system plays a central role in the management of human capital since it cuts across other HR functions (Fombrun et al., 1984). More details are discussed in the following.

\section{Organizational Culture}

The organizational culture is a system of shared values that define what appropriate behaviors and attitudes are (O'Reilly and Chatman, 1996). It is closely related to the idea of control through socialization and internalization of value systems. Artifacts and behavioral manifestations are of interest in terms of attributed meanings. In our framework, the organizational culture embodies an underlying ideology, which directs and aligns behaviors and organizational design. In addition to the publicly espoused and endorsed ideology, the subculture of knowledge workers is of interest, too, since they are observed to follow a different set of norms (Tampoe, 1993; May et al., 2002; Swart, 2007).

In our analysis, attention is directed to four elements of the organizational culture (Sackman, 1992): (a) the "dictionary element" refers to commonly shared language and definitions; (b) the "directory element" involves commonly held practices; (c) the "recipe" refers to commonly prescribed 
recipes for improving knowledge output; (d) the "axiomatic element" refers to common assumptions about knowledge work.

\section{Organizational Structure}

Organizational structure provides organizations with patterned regularity. Scott (2003) argues that bureaucratic controls represent important instances of impersonal controls. Control is usually achieved by means of formalization of tasks, work systems, procedures, layout of offices, technology and so on. Nevertheless, structure is never static and complete. Unspecified space and ambiguity exist and represent opportunities to improvise (Hatch, 1999). It is also observed that on top of formal work relations, we use emotions such as liking and interpersonal attraction to form work relations. These informal relations control actors through emotional bonds.

Relating to knowledge management, we define organizational structure as communication channels where information or knowledge travel through and communication takes place. These channels craft and groom communicative behaviors within organizations. They also function as an enabling platform for actors' autonomous behaviors (Giddens, 1979). However, knowledge workers work at inter-organizational levels. Our analysis investigates the formalization and emotionality in the communication channels within and beyond organizational boundaries.

\section{Appraisal System}

The appraisal system is a powerful mechanism to encourage desired behaviors and mentality among employees. It sends clear signals about what behaviors and mentality are appropriate. Control is usually achieved by means of rewards, sanctions, training and development. In the Michigan model of human resource management (Fombrun et al., 1984), appraisal cuts across boundaries of traditional HRM functions (see Figure 1). It interlocks performance to development and reward decisions, fulfilling the administrative purpose by sorting performance and the developmental purpose by subsequent training and coaching. Any discussion on appraisal will be incomplete without considering the sorting and the informing effects. As such, an appraisal system is conceptualized as a diagnostic tool to differentiate performance and to inform and foster a desirable mentality and skills.

Today multi-source feedback is a common practice in about one in five firms (Armour, 2003) or even more. The fact is that different stakeholders may adopt different criteria. Are appraisals by other constituents considered valid or relevant by knowledge workers? Or can knowledge work be appraised objectively and quantitatively? These are issues to be addressed in our subsequent analysis.

\section{IT infrastructure}

Information technologies (IT) probably are one of the most deeply-rooted rationalized myths nowadays. They not only support our daily work, but also regulate it (Scott, 2003). A broad definition suggests that it is "the set of mechanical, knowledge and human technologies used to convert inputs into outputs" (Collins et al., 1986). For the analytical purpose here, IT infrastructure is restricted to material artifacts or devices used to manage or facilitate information flows. We sustain the artificial distinction between the material nature and the human activities so as to observe the potential interplay between aspects of presumed functionalities and actual usage.

Laudon and Laudon (1999) categorize KM tools into four groups: tools for knowledge capture and codification, tools for knowledge sharing, tools for knowledge distribution, and tools for knowledge creation. The categorization indicates three purposes that technology may possibly fulfill, namely the instrumental (efficient knowledge reuse through automation), the communicative (building consensus through knowledge sharing/distribution) and the self-actualizing (knowledge creation) purposes. Control is to be achieved by means of presumed functionalities and by making work processes 
visible since IT cannot solve unforeseen contingencies. However, knowledge is embedded in social structures, so to what extent can knowledge be managed by IT infrastructure? Despite efforts to control through inscription, is actual use of IT infrastructure always as anticipated?

Finally, it is noteworthy that research focusing on the impact of individual control mechanisms may produce misleading results. The concept of "organizational logic"
(MacDuffie, 1995) is important. It refers to a systemic property that engenders integral relationships among control mechanisms. Based upon this framework, we further investigate the logic that organizes the four control mechanisms. Table 1 is a summary of our analytical framework comprised of the four control mechanisms. The definition, comprising aspects and the way to achieve control of each control mechanism are specified.

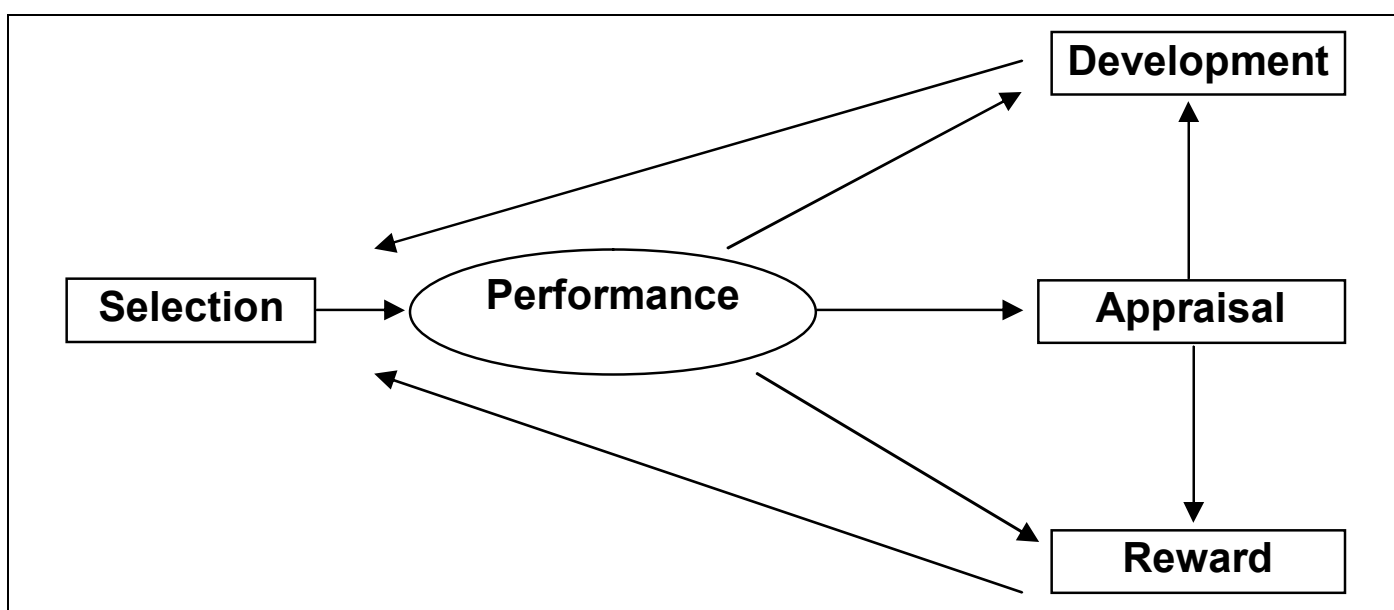

Figure 1- Michigan model of HRM (Fombrun et al., 1984)

\begin{tabular}{|c|c|c|c|}
\hline & Definition & Aspects & How to achieve control \\
\hline $\begin{array}{l}\text { Organizational } \\
\text { culture }\end{array}$ & $\begin{array}{l}\text { An underlying ideology } \\
\text { which directs and aligns } \\
\text { behaviors and } \\
\text { organizational design. }\end{array}$ & $\begin{array}{ll}\text { - } & \text { Dictionary element } \\
\text { - } & \text { Directory element } \\
\text { - } & \text { Recipe } \\
\text { - } & \text { Axiomatic element }\end{array}$ & $\begin{array}{ll}\text { - } & \text { Socialization } \\
\text { - } & \text { Internalization }\end{array}$ \\
\hline $\begin{array}{l}\text { Organizational } \\
\text { structure }\end{array}$ & $\begin{array}{l}\text { Communication channels, } \\
\text { including both formalized } \\
\text { and emotionality-based } \\
\text { channels. }\end{array}$ & $\begin{array}{l}\cdot \quad \text { Formal work } \\
\text { processes } \\
\cdot \quad \text { Informal interaction } \\
\text { patterns }\end{array}$ & $\begin{array}{ll}\cdot \text { - } & \text { Formalization } \\
\text { - Emotional bond }\end{array}$ \\
\hline $\begin{array}{l}\text { Appraisal } \\
\text { system }\end{array}$ & $\begin{array}{l}\text { A diagnostic tool to } \\
\text { differentiate performance } \\
\text { and to inform and foster a } \\
\text { desirable mentality and } \\
\text { skills. }\end{array}$ & $\begin{array}{l}\text { - } \text { Sorting effect } \\
\text { - Informing effect }\end{array}$ & $\begin{array}{l}\text { - Rewards and sanction } \\
\text { - Training and } \\
\text { development }\end{array}$ \\
\hline IT infrastructure & $\begin{array}{l}\text { Artifacts or devices used to } \\
\text { manage or facilitate } \\
\text { information flow. }\end{array}$ & $\begin{array}{l}\cdot \quad \text { Tools for knowledge } \\
\text { capture and codification } \\
\cdot \quad \text { Tools for knowledge } \\
\text { sharing } \\
\text { - Tools for knowledge } \\
\text { distribution } \\
\text { c Tools for knowledge } \\
\text { creation } \\
\end{array}$ & $\begin{array}{l}\cdot \text { Control by presumed } \\
\text { functionalities } \\
\cdot \quad \text { Making work } \\
\text { processes visible }\end{array}$ \\
\hline
\end{tabular}




\section{Methodology}

This paper adopted the strategy of single case study. To ensure an illuminating case was found, criteria were set: the case company had to (1) hire at least five in-house translators and two administrative staff and (2) have been in trading for three consecutive years. The first criterion was chosen on the grounds that interpersonal interaction takes at least two persons to become possible, and most translation agencies tend to deal with at least one language-set in two directions (e.g. "from English to Chinese" and "from Chinese to English"). As such, there will be two dyads interacting. However, complex sociological processes such as coalitions or mediation only exist within a three-person group or above (Kilduff and Tsai, 2003). , we set five in-house translators as the threshold. The second criterion is straightforward since we intend to learn from a successful case.

Potential corporate members registered with Association of Translation Companies (ATC) were accessed by e-mail, inquired about the size, duration in business and application of computing technologies. ATC is a professional body which provides legal services, advices and business referrals as well as courses or conferences concerning the translation industry in UK. It imposes codes of practices on members and has certain degree of authority to influence legislation about the translation industry in Britain and Europe. A pilot survey indicated that over half of the registered companies mainly engaged in virtual project management with minimal presence of in-house translators. Nevertheless, each of these companies claimed to have a tremendous freelancer pool. After being advised of the research purpose and procedures, 12 companies were interested. Among them, only 2 met our criteria. In the end, AA consented to be studied. Data then was collected in July and August of 2002.

Collection methods consisted of semi-structured interviews, and document and website content analysis. The interviews were conducted and tape recorded in AA's London premises with the Director of Operation, two Project Managers and two in-house translators, each lasting over one hour. Except for some signposts and question posing during conversations, interviews were actually allowed to emerge and drift. Factual data collected from one interview was triangulated with other interviews or documents. Doing so helped us reconcile differences between espoused and actual practices. However, perceptions were not suitable for cross-checking as they reflected different belief systems and required further examination.

To ensure reliability and comparability, 2 interview protocols were developed, one for the management and the other for translators, including questions about facts and perceptions on organizational culture, organizational structure, appraisal system and IT infrastructure. Overall, the two protocols were very similar. Only that managerial intention was usually asked of the managers, and perception about practices or policies was asked of translators. In the interview protocols, space was left for recording the interviewer's comments and jotting down signposts to facilitate later transcription. Contents of transcription then were categorized and analyzed into four major categories (organizational culture, organizational structure, appraisal system and IT infrastructure). Two additional categories were established, namely new topics and leftovers.

\section{Case Analysis}

AA was a registered member of two professional bodies-Institute of translation and interpreting (ITI) and Association of Translation Companies (ATC). It had been in business since 1974 with office locations in Bristol and London. The Bristol office was responsible for technical authoring of English manuals, and the London office was charged 
When High Touch Meets Low Tech: Knowledge Management in a Small Enterprise/Liu \& Wang

with translation, interpretation, desktop publishing and printing. This paper is based on research conducted in its London premises. Eleven out of the fourteen people working in the 2-floor London office are within our research scope. They are eight translators and three administrative staff (Director of Operation and two project managers) working on the same floor. Three other are technical staff in charge of desktop publishing and printing.

\section{The Primary Tone: An Open and Sharing Organizational Culture}

An open and sharing culture was staged in AA through explicit advocacy by the management, accompanied by practices designed to reinforce it or at least to increase socialization. These practices included team-up of in-house translators to crosscheck each other's rendition, participation in common projects, an open-door policy of the management, and open layout of the office. As such, according to the Director of Operation, "mucking around" and voluntary proofreading gradually became an acceptable behavior and a routine. Among the eight translators, a high degree of trust and respect for each other's expertise was developed and accumulated over a long history of interaction. Four of them had been working in $\mathrm{AA}$ for over five years, with the most senior one for over 13 years and the least senior one for over one year.

Challenges and varieties of everyday tasks were usually cast in a positive light by both the management and the translators. In fact, it was one of the reasons the translators chose to work for the translation agency. The management had high praise for those translators who were honest about their ability and willing to take up a text that was not strictly within their specialty. Through daily practices and constant socialization, a positive language and attitudes towards challenges and knowledge sharing were developed and shared among all participants. Alignment of the dictionary element and the directory element had set a primary tone for
AA's organizational culture.

\section{Subcultures: My Pace or Yours?}

Discrepancy between the translators and the managers was observed. Translators tended to follow a self-imposed work pace. As one translator put it, "...so I would say this is taking me all morning to do so many words, so therefore I won't meet the deadline unless the rest part starts to get a lot easier." For translators, no specific processes would dictate translation tasks. Each translation task was a new experience and required different amount of time spent on research. Even for highly repetitive texts, rarely were their contexts the same, and human judgment and creativity were always required. Discrepancy of perceptions about overwork was also obvious. Although overwork could temporarily increase knowledge output, it was never an optimal option for translators for it might sacrifice the output quality. "Translation is quite a mentally demanding job... and you do another 2 or 3 hours at home. You can do that, but the next day, you are not fresh," said one translator

In contrast, the management strictly adhered to a timeframe externally imposed by the client. Coordination of knowledge tasks was conceived as "an automatic and standard process." Project managers usually would "get the information that is needed for the translation and hand out the deadline, format, and information to translators." Translators referred to the management as "one of the sales, marketing and satisfying the customers' needs." For the management, overwork was something praise-worth to meet requirements of clients and deadlines were something that could not be compromised. Director of Operation reported:

We give them [freelance translators] an assignment to do. We basically want them to do it within the timeframe. If they say they will have something done by Friday afternoon...if I don't see it on Friday afternoon, they probably won't work for us again. 
Concurrent with many research (Hamel, 1991; Davenport and Prusak, 1998), the open and sharing culture, respect and trust in expertise were observed to facilitate knowledge transfer and sharing in our case. Physical proximity and participation in joint activities also significantly increased socialization. Nevertheless, differences in work paces and assumptions of knowledge work generated tensions especially when the knowledge "production process" did not proceed as expected. Strictly adhering to the externally imposed work pace and assuming knowledge coordination as standard and automatic by the management were considered to be disadvantageous for learning and knowledge creation. In summary, on the surface, although an open and sharing culture was endorsed and espoused in both dictionary and directory elements, subcultures of the translators and the management manifested deep-down difference in the recipe and axiomatic elements.

\section{Organizational Structure}

In $\mathrm{AA}$, the organizational structure was flat. Except for the formal reporting relationships between Director of Operation and the project managers, there were no superior-subordinate relationships between the project managers and the translators. Activities were connected and coordinated in the unit of projects, which were considered to be "the second most important part of a translation company after translation," according to a project manager. Size and duration of project teams were contingent on the size and urgency of a translation task, and when tasks ended, teams were disbanded. Project managers were always charged with all administrative responsibilities and the maintenance of databases that captured information about freelance translators, clients, terminologies, and past translation works, and only the management had a full access right to the database.

\section{Intra-firm Channels}

Overall, formal communication channels in AA were minimal partly due to its relatively small size. These channels included the design of project teams and daily job sheets that specified how translation tasks needed to be done with supplement information about the tasks at hand. One column on the job sheet was "reviewer" which needed to be signed after being proofread by a voluntary reviewer. Information or knowledge transferred through these formal channels was mostly lists of glossary, requirements from clients, or relevant information retrieved from databases. This information was perceived to be less problematic and straightforward, and, most of the time, had been verified by clients and stored as corporate memory.

Apart from the formal channels, informal channels were developed based upon similarities of expertise or interpersonal liking. One translator reported:

We work together with people with the same language combinations so we often cross check each other's work... Occasionally somebody might ask, have you got this phrase? Or there is something that can't be found in the dictionary or internet. Then we might discuss it.

These intra-firm informal channels, based upon respect and trust in each other's expertise and facilitated by physical proximity, benefited not only sharing of implicit knowledge but also the development of new knowledge. In summary, formal and informal channels within AA were observed to facilitate the application, transfer and distribution of dispersed knowledge that already existed in AA. The informal channels even provided a more intimate and personal context for the development of new knowledge via face-to-face communication.

\section{Channels Beyond the Firm Boundaries}

All the translators came to $A A$ as a second career. Before joining $A A$, most of them used to work in the field of higher education. Their educational background and nationalities showed a moderate level of diversity -6 with 
When High Touch Meets Low Tech: Knowledge Management in a Small Enterprise/Liu \& Wang

a degree in language and linguistics, 4 with a diploma or degree in translation; six Britons, one Spaniard and one Frenchman. To acquire new perspectives or knowledge, apart from discussing with colleagues, translators sometimes looked outwards. One translator said:

Sometimes I email friends who have expertise in my language combination for their thoughts on particularly obscure references...if only to get a range of views. As my friends are a range of native German speakers and translators, I find this an interesting way of finding solutions.

As the example showed, social networks of these translators extended far beyond organizational and even cultural boundaries. After acquiring new knowledge, the in-house translators sometimes cross-pollinated among themselves through the exchange of "hearsay". Along with the intra-firm channels, their social networks not only benefited the focal translators, but also those who they worked with or liked to work with. However, these networks also came with a cost-the threat of labor mobility. One translator indicated:

Here the good thing about working in an agency is that you got lots of experiences in different areas... [career aspirations are] to acquire work which is in areas suited to my own interests and abilities, rather than subject areas that I find rather dry, and be able to work from home with a steady flow of work, with an excellent rate of pay.

The translators were committed to their profession and were willing to accept the employment that might enhance their employability in the long run. They were also aware of the market value of their skills through casual exchange of the "hearsay". In summary, the management of AA did pay duly attention to the management of intra-firm channels by deliberately designing formal channels to induce informal ones, but they were not fully aware of the potential value and threat of outside, informal channels the translators possessed.

\section{Appraisal System}

In AA, appraisal was relatively responsive and usually involved managers, clients and colleagues. In addition to a yearly appraisal, the management tended to "deal with any issues that may rise as they rise rather than waiting till the appraisal time." Although there were no written handbooks or regulations stipulating rewarded behaviors or outcomes, certain behaviors were constantly stressed by the management, including "to be honest about what they can and cannot do, and be prepared to take on challenges." In addition, the management also focused on some quantitative indicators, including deadlines, accomplished project numbers, and numbers of clients' complaints. Among them, meeting deadlines was regarded to be the most basic requirement by both the management and the translators. Feedback on the speed, accuracy or styles mostly came from the peers, and occasionally from clients. In $\mathrm{AA}$, there were three levels of translation. The first level required the same translator to translate and proofread. The second level requires two or more translators. One translated and the others did the checking. The third level ideally would involve translators with specialized knowledge. Clients' comments were not always available. However, negative feedback from them, mediated by the management, was not always accepted warmly, as one translator perceived queries from clients to be "either that it's a sort of their company's specific way of expressing something or may just be that no language can be translated exactly word for word because there are all sorts of culture concepts."

\section{From Appraisal to Training and Development}

In AA, appraisal also did not lead to formal training or development programs, and upskilling was considered to be the responsibility of each translator. Formal training did not exist, not even an orientation program for newcomers because translators 
were expected to come with qualifications and experiences. Informal mentoring, on-the-job training and self-learning took place through consulting with other translators, reading on their own or researching on any topic on the internet. The block where translators worked was described to be "like a library" and was equipped with reference books and newspapers. Davenport and Prusak (1998) found that $70-80 \%$ of learning was done through informal methods in the 39 organizations they observed. In our case, the percentage probably rose up to $99 \%$. On the one hand, the management expected the translators to learn continuously and exchanged performance for employment. They abandoned the conventional paternal style to adopt the role of a mediator and a facilitator. Further, by keeping many qualified freelancers at the arm's length, AA had a fluid and flexible workforce. On the other hand, these in-house translators enjoyed their autonomy very much, and identified with other translators more than with the organization or their clients. A new psychological contract which stressed self-management was found to set foot firmly in our case.

In general, appraisal in AA involved multiple agents, and feedback on behaviors and outcomes were not explicitly linked to extrinsic rewards, such as promotion or monetary rewards. Although the translators were somewhat willing to give up the peripheral part of their autonomy to the behavioral and quantitative control conceived by the management, they were reluctant to accept criticism on their expertise from those who they deemed as laymen. Rather than sorting performance, the appraisal system of AA provided useful information for the translators to self-manage their own behaviors and knowledge output. Contrary to our intuition, ignorance of the sorting effect of appraisal did not give rise to the issue of equity. This might be due to a high level of respect and trust in each other's expertise among the translators and their common assumptions about knowledge and knowledge work. Instead of achieving control by rewards, sanction or training, the appraisal system in AA achieved control by mutual acceptance of the new psychological contract.

\section{IT infrastructure}

IT infrastructure in AA was rather basic and unimpressive. Installed information technologies included Microsoft Office programs, the internet and a translation tool, Trados. Trados boasted a translation memory which accumulated from every translation task, and could automatically retrieve precise or fuzzy match of certain words or phrases. Maintenance and update of the translation memory in Trados usually rested upon the shoulders of translators. It was very efficient in translating highly repetitive texts, such as technical manuals or graphical user interfaces (GUI) of computer software. Although translation memory could be used to translate automatically given enough memory accumulated, it also required human judgment to check whether the renditions made sense in the linguistic or the contextual point of view. Overall, Trados was rarely used due to its incompatibility with Office programs, lack of contextual information and the low repetitiveness of most texts. On the other hand, most of the work is translated in the environment of Microsoft Office programs and researched into certain topics on the internet, along with relevant information retrieved from intra-firm database. After each translation task, the project managers would collect new terminologies from the clients and translators and store them in the database. In AA, there were two important databases storing information about clients and freelance translators. In the client database were each client's contact information, special requirements or terminologies, and previous translation works, whereas in the freelance database were personal information and special requirements of each translator.

These databases and the translation memory in Trados were presumed to capture knowledge and facilitate its reuse and distribution. However, information stored in the databases and maintained by project managers was perceived to be of no use or 
obsolete due to the lack of contextual information. Further, incompatibility between Trados and Office programs also reduced the combinability and interbreeding of information. In contrast, information on the internet was considered to be more useful and timely by the translators. Given the convolution and tacitness of texts, the translators appreciated more the technologies by which they would be able to access relevant contextual information than those providing access to knowledge stock or glossary lists. Although IT infrastructure in AA was originally designed to facilitate the reuse of knowledge, actual usage of the infrastructure was not precisely as expected due to the failure to consider the contextual and motivational factors. However, connectivity and accessibility promised by the internet facilitated knowledge creation at the individual level through online self-learning.

\section{Discussion}

Table 2 summarizes our analysis concerning the four control mechanisms. It was found that knowledge management in AA was facilitated by many factors, including an open and sharing culture, tolerance of the subculture of knowledge workers, intra-firm communication channels based upon respect and trust in each other's expertise, an appraisal system buttressed by the new psychological contract, connectivity and accessibility promised by the internet, and a flexible workforce supplemented by qualified freelancers. Inhibitors included a mass-production mentality of the managers, the negligence of potential value and threat of social networks beyond firm boundaries, unfamiliarity and incompatibility of tools, and decontextualized knowledge stock. However, to conclude that an open and sharing culture, smooth communication channels, appraisal information and a web-based IT infrastructure are the panacea contributes little to the understanding of $\mathrm{KM}$ in contexts. The deductive and inductive case study allowed us to pinpoint the underlying logic which organized and drove the configuration of the four control mechanisms in AA.
First, our case depicted a small management team, not only literally in its size but also in its authority. The hands-off style of management left substantial leeway for the translators to enact the organizational reality and to "fill in" what they believe to be appropriate. Diversity and idiosyncrasy was not eliminated, but was oriented towards a sense of unity which was expressed "at a level of abstraction" (Eisenberg, 1984), referred to as an open and sharing organizational culture and a new psychological contract of self management. Under the implicit frame, freedom was imparted to the translators to step outside the frame to network, to create, to share, to socialize, to practice their skills and to manage work paces in less urgent cases. Only minimal managerial efforts revolved around the dictionary and directory elements of organizational culture without forcing out fundamental difference in the deeply-rooted recipe and axiomatic elements. From this, a low formalization and high touch paradigm gradually took shape.

Second, the existent formal organizational structure provided routes for existent knowledge to flow and for its members to converse and communicate. Through conversations, knowledge workers discovered what they knew, shared it and in the process created new knowledge (Webber, 1993). Although respect and trust in expertise was fostered through constant interaction, trust in this context was not purely a "human passion" that is "the confident expectation of the benign intentions by another agent" (Dunn, 1988), but a calculative action (Williamson, 1993). It was observed that the translators acquired or shared knowledge based upon their rational calculation of the credibility and similarity of other translators' expertise. Trust in our case specifically referred to 'trust in expertise'. Apart from intra-firm channels, channels beyond firm boundaries received less managerial attention in AA. They remained capital exclusively owned by each translator. Nevertheless, the possibility exists to make networking behaviors a virtuous circle between the individual and the organization. Only that the management must 
be mindful of how they encourage the translators to network in such a way as to stay in the organization (Sturges et al., 2002).

Third, feedback from clients, colleagues and formal quantitative indicators were employed to appraise knowledge output and behaviors. However, by loosely coupling these indicators with rewards and training, authority of these indicators was not enforced. Rather, these indicators informed what were expected from the translators, with the hope that that it would produce self-fulfilling prophecies. To sustain the operation of the informal appraisal system, the notion of self-management permeated the organizational fabric of AA. It was noticed that the translators were active in investing in human capital, networking with other professionals, taking up challenges to broaden and deepen their expertise, and negotiating work/non-work boundary by refusing or accepting extra workload outside work hours (King, 2004). In comparison, except for providing appraisal information for autonomous adjustment, self-management help from the organization appeared to be meager, partially reflecting innate resource constraints of small organizations.

Finally, the IT infrastructure of AA was originally designed for collecting information. Two types of information were identified, one collected by the management and the other accumulating in Trados. First, storage of information about freelancers afforded $A A$ a flexible and fluid knowledgeable workforce across organizational boundaries. Nevertheless, the glossaries stored did not benefit the core knowledge work very much because information was decontextualized. Second, compared with glossaries collected and stored by the managers, Trados could capture contextual information. Nevertheless, unfamiliarity, low motivation and incompatibility with Microsoft programs reduced its popularity. While the objective of knowledge capture and codification was not quite accomplished, the web-based IT infrastructure accomplished an unexpected objective of knowledge discovery and facilitated knowledge creation at the individual level.

The upshot is that knowledge management in small organizations is not something new and does not require radically different control mechanisms or advanced IT infrastructure (Moffett and McAdam, 2006; Hutchinson and Quintas, 2008). Rather, it is the organizational logic that may vary and in turn leads to different configurations and combinations of these mechanisms. Control mechanisms, as one type of institutions, tend to exist in systems, with one tuned to another (Nelson, 2008). In addition to the organizational size, the self management logic appeared to prime the minimalist design and combination of these control mechanisms in AA. Lessons from previous studies reveal that successful $\mathrm{KM}$ requires open and sharing culture and effective communication (Hamel, 1991; Quinn, 1992). These requirements appear to readily fit the inherent characteristics of small organizations, such as rapid response to environmental changes, flat and organic structure, and absence of functional mindset. Small organizations do not really suffer from resource constraints. In fact, they may be privileged.

\section{Conclusion and Implications}

Past research on $\mathrm{KM}$ practices has often implied a universalistic prescription for all sizes of organizations and failed to recognize the multiple and reinforcing relationships among control mechanisms. We use the four control mechanisms to gauge and capture the organizational logic that indicates a preferred direction for the organizational design and behaviors. It is observed that the new psychological contract and the small organizational size jointly cause the laissez-faire style of joint knowledge management. 


\begin{tabular}{|c|c|c|}
\hline & Facilitators & Inhibitors \\
\hline $\begin{array}{l}\text { Organizational } \\
\text { culture }\end{array}$ & $\begin{array}{l}\text { - The primary tone of an open and sharing } \\
\text { culture, set by the dictionary element (rhetoric, } \\
\text { discourse) and the directory element (physical } \\
\text { proximity, participation in joint activities), was } \\
\text { found conducive to knowledge sharing and } \\
\text { distribution. } \\
\text { - Discrepancies of subcultures (the recipe and } \\
\text { axiomatic element) were tolerated. }\end{array}$ & $\begin{array}{l}\cdot \text { A mass-production mentality of } \\
\text { the management, such as the } \\
\text { externally imposed work pace and } \\
\text { regarding knowledge work to be } \\
\text { standard and automatic, impeded } \\
\text { learning and knowledge creation. }\end{array}$ \\
\hline $\begin{array}{l}\text { Organizational } \\
\text { structure }\end{array}$ & $\begin{array}{l}\text { - Minimal formal channels were conducive to } \\
\text { the emergence of informal bonds, and these } \\
\text { intra-firm channels altogether provided routes for } \\
\text { existent knowledge. } \\
\text { and The informal channels, based upon respect } \\
\text { and trust in each other's expertise, were } \\
\text { conducive for development of new knowledge. }\end{array}$ & $\begin{array}{l}\text { The management was not aware } \\
\text { of the potential value and threat of the } \\
\text { social networks possessed by the } \\
\text { translators that were beyond the firm } \\
\text { boundaries. }\end{array}$ \\
\hline Appraisal system & $\begin{array}{l}\text { - A new psychological contract of } \\
\text { self-management buttressed the appraisal } \\
\text { system. } \\
\text { - Appraisal provided useful information for the } \\
\text { translators to self-manage their own behaviors } \\
\text { and knowledge output. } \\
\text { - Issues (e.g. equity) related to the ignorance } \\
\text { of sorting effect of appraisal were possibly } \\
\text { mitigated by a high level of respect in each } \\
\text { other's expertise among translators and their } \\
\text { common assumptions about knowledge and } \\
\text { knowledge work. }\end{array}$ & - Not found \\
\hline IT infrastructure & $\begin{array}{l}\text { - Connectivity and accessibility promised by } \\
\text { the internet facilitated knowledge creation at the } \\
\text { individual level. } \\
\text { - Stored information about qualified } \\
\text { freelancers afforded a flexible workforce. }\end{array}$ & $\begin{array}{l}\text { - Translators were not motivated to } \\
\text { use Trados because of unfamiliarity } \\
\text { and its being incompatible with the } \\
\text { Microsoft programs. } \\
\text { - Stored and decontextualized } \\
\text { glossaries were perceived to be } \\
\text { obsolete and useless. }\end{array}$ \\
\hline
\end{tabular}

This case suggests one useful prototype for managing individualistic and independent knowledge work in small organizations, such as industrial design and software programming. In conclusion, we find that all participants engaged in the management of knowledge in the small enterprise. On the one hand, participants managed themselves through (a) the buy-in of an open and sharing culture and the new psychological contract, (b) information from the appraisal results, and (c) conversation and communication with other experts. On the other hand, facing powerful knowledge workers, the management employed (a) a strategy centered on using the dictionary and directory elements of an open and sharing culture, (b) minimal interventions to induce and structure spontaneous communication, and (c) freelancers to complement expertise within organizational boundaries.

An immediate implication of our finding is that a configurational approach to $\mathrm{KM}$ is useful to generate typologies or taxonomies that exhaust a large fraction of $\mathrm{KM}$ styles in different sizes of organizations. In addition, the present case contributes to the understanding of knowledge management in 
numerous ways. First, by treating knowledge as social capital, we clarify that knowledge management inevitably involves the management of cognitive resources and structures where the resources are embedded. However, discontinuous from the social community perspective, we discover that commitment and trust usually is conditional upon credibility and similarity of expertise. Second, our framework also unfolds the structural and processual characteristics of each control mechanism. Although each control mechanism can be classified to be formal or social according to their dominant structural characteristics, performatively the line between the formal and the social is sometimes retrospectively drawn dependent upon whether control is actually achieved through internalization or formal authority. The appraisal system in our case is an illustration. Moreover, the processual characteristics reveal the way control may possibly be achieved. Third, instead of an employer-centered command and control model or an employee-centered high-commitment model, a joint management model is identified. There are always conflicts and shared interests in any employment

\section{Reference}

Armour, S. (2003) "Job Review Take on Added Significance in Down Times", USA Today, pp. 6A-7A.

Barley, S. R. And Kunda, G. (1992) "Design and Devotion: The Ebb And Flow Of Rational And Normative Ideologies of Control in Managerial Discourse", Administrative Science Quarterly 37, pp. 1-30.

Barney, J. (1991) "Firm Resources And Sustained Competitive Advantage", Journal of Managemen 17, pp. 99-120.

Baron, J. N., M. T. Hannan, and M. D. Burton (2001) "Labor Pains: Change In Organizational Models and Employee Turnover in Young, High-Tech Firms", relationship. Managing knowledge workers abstractly by an open and sharing organizational culture and the new psychological contract of self-management can possibly accommodate divergent interests, belief systems and identities as our case illustrates. An immediate ramification is that satisfying knowledge workers' interests implicates paying them at the market-based rate since they are usually aware of their market value and allocation of returns is not so difficult in highly individualistic knowledge work. Hence, the issue of rent appropriation probably should be reinterpreted as an issue of rent sharing between partners. Fourth, viewing organizations as a structuring and enabling context covered with communication channels steers clear of the danger of personating organizations as thinking entities, and offers managers guidance as to how to intervene the communication and the interaction among knowledge workers. Despite of the connection, disconnection is a supportive absence. It invited members to bridge the gap (Hatch, 1999; Cooper, 2005) when gradually primed by cues extracted from an open and sharing culture and the new psychological contract.

American Journal of Sociology 106 (4), pp. 960-1020.

Bourdieu, P. and L. Wacquant (1992) An Invitation To Reflexive Sociology, University Of Chicago Press, Chicago.

Braverman, H. (1974) Labor and Monopoly Capital, Monthly Review Press, NY.

Coleman, J. S. (1994) Foundations Of Social Theory, Belknap Press, Cambridge.

Collins, P.D., J. Hage, and F. Hull (1986) A Framework For Analyzing Technical Systems In Complex Organizations, In Research In The Sociology Of Organizations, Vol. 6, Greenwich, CT: JAI Press.

Cooper, R. (2005) "Relationality", Organization Studies 26 (11), pp. 
When High Touch Meets Low Tech: Knowledge Management in a Small Enterprise/Liu \& Wang

1689-1710.

Davenport, T.H. and L. Prusak (1998) Working Knowledge, Harvard Business School Press, Boston.

Dunn, J. (1988) Trust And Political Agency, In D. Gambetta (Ed.), Trust: Making And Breaking Cooperative Relations, Basil Blackwell, Oxford.

Eisenberg, E. M. (1984) "Ambiguity As Strategy in Organizational Communication", Communication Monographs 51, pp. 227-42.

Fernandez, R. M., E. J. Castilla and P. Moore (2000) "Social Capital at Work: Networks and Employment at a Phone Center", American Journal Of Sociology 105, pp. 1288-1356.

Fombrun, C.J., N. M. Tichy and M. A. Devanna (1984) Strategic Human Resource Management, Wiley \& Sons, New York.

Gibson, C. B. (1999) "Do They Do What They Believe They Can? Group-Efficacy Beliefs And Group Performance Across Tasks And Cultures", Academy Of Management Journal 42, p. 138-152.

Giddens, A. (1979) Central Problems In Social Theory: Action, Structure, and Contradiction in Social Analysis. University Of California Press, Berkeley.

Glaeser, E. L., D. I. Laibson, J. A. Scheinkman and C. L. Soutter (2000) "Measuring Trust", The Quarterly Journal Of Economics 115, pp. 811-846.

Ghobadian, A. and D. N. Gallear (1996) "Total Quality Management In Smes", Omega 24(1), pp. 83-106.

Granovetter, M. S. (1973) "The Strength Of Weak Ties", American Journal of Sociology 78, pp. 1360-1380.

Granovetter, M. S. (1992), "Problems Of Explanation In Economic Sociology", in N. Nohria And R. Eccles (Eds.), Networks And Organizations: Structure, Form And Action, Harvard Business
School Press, Boston, p. 25-56.

Grant, R. M. (1996) "Toward A Knowledge-Based Theory o The Firm", Strategic Management Journal 17, p. 109-122.

Hamel, G. (1991). "Competition For Competence And Inter-Partner Learning With International Strategic Alliances", Strategic Management Journal, Vol. 12 No. 2, Pp. 83-103.

Hatch, M. J. (1999) "Exploring The Empty Spaces of Organizing: How Improvisational Jazz Helps Redescribe Organizational Structure", Organization Studies 20, pp. 75-100.

Hutchinson, V. and Quintas, P. (2008) "Do Smes Do Knowledge Management", International Small Business Journal 26(2), pp. 131-154.

Kilduff, M. and W. Tsai (2003), Social Network And Organizations. Sage: London.

King, Z. (2004) "Career Self-Management: Its Nature, Causes And Consequences", Journal of Vocational Behavior 65, pp. 112-133.

Laudon, K. C. And J. P. Laudon (1999), Management Information Systems: Organization And Technology In The Networked Enterprise (6 ${ }^{\text {th }}$ Edition). Prentice Hall: Englewood Cliffs, NJ.

Lyon, A. (2005) "Intellectual Capital and Struggles Over the Perceived Value of Members' Expert Knowledge in A Knowledge-Intensive Organization", Western Journal Of Communication 69(3), pp. 251-271.

Macduffie, J. P. (1995) "Human Resource Bundles and Manufacturing Performance: Organizational Logic and Flexible Production Systems in The World Auto Industry", Industrial And Labor Relations Review 48(2), pp. 197-221.

May, T. Y., M. Korczynski and S. J. Frenkel (2002) "Organizational and Occupational Commitment: Knowledge Workers in Large Organizations", 
Journal Of Management Studies 39(6), pp. $775-801$.

Mcadam, R. and R. Reid (2001) "SME and Large Organization Perceptions of Knowledge Management: Comparisons And Contrasts", Journal Of Knowledge Management 5(3), pp. 231-241.

Moffett, S. and R. Mcadam (2006) "The Effects of Organizational Size on Knowledge Management: Opportunities For Small Firms? " Total Quality Management 17(2), pp. 221-241.

Nahapiet, J. and S. Ghoshal (1998) "Social Capital, Intellectual Capital, and the Organizational Advantage", Academy Of Management Review 23 (2), pp. 242-266.

Nelson, R.R. (2008) "What Enables Rapid Economic Progress: What Are The Needed Institutions? " Research Policy 37, pp. 1-11.

O'Reilly, C. A. III and J. A. Chatman (1996) "Culture As Social Control: Corporations, Cults, And Commitment", Research In Organizational Behavior 18, pp. 157-200.

Putnam, R.D. (1993) "The Prosperous Community: Social Capital and Public Life", The American Prospect 4, pp. 11-18.

Quinn, J. B. (1992) Intelligent Enterprise : A Knowledge And Service Based Paradigm For Industry, The Free Press, New York.

Robinson, R. B. (1982) "The Importance of Outsiders in Small Firm Strategic Planning", Academy Of Management Journal 25 (1), pp. 80-93.

Sackman, S. A. (1992), "Culture and Subcultures : An Analysis of Organizational Knowledge", Administrative Science Quarterly 3, pp. 140-161.
Scott, W. R. (2003) Organizations: Rational, Natural And Open Systems, Prentice Hall: US.

Storey, J. and P. Quintas (2001) "Knowledge Management and HRM" in Storey, J. (Ed.). Human Resource Management: A Critical Text. Thomson Learning, London.

Sturges, J., D. Guest, N. Conway and K. M. Davey (2002) "A Longitudinal Study of the Relationship Between Career Management and Organizational Commitment Among Graduates in the First Ten Years at Work", Journal of Organizational Behavior 23 (6), pp. 731-748.

Swart, J. (2007) "HRM And Knowledge Workers", in Boxall, P., Purcell, J. And Wright, P. (Eds.). The Oxford Handbook of Human Resource Management. Oxford University Press, Oxford.

Tampoe, M. (1993) "Motivating Knowledge Workers: The Challenge for The 1990s", Long Range Planning 26 (3), pp. 49-55.

Webber, A. M. (1993) "What's So New About The New Economy?", Harvard Business Review. Jan.-Feb.

Weick, K. E. And Roberts, K. (1993) Collective Minds in Organizations: Heedful Interrelating on Flight Decks, Administrative Science Quarterly 38, pp. 357-381.

Williamson, O. E. (1993) "Calculativeness, Trust, and Economic Organization", Journal of Law \& Economics 36, pp. 453-486

Wright, P.M., G. C. Mcmahan and A. Mcwilliams (1994) "Human Resources and Sustained Competitive Advantage: a Resource-Based Perspective", International Journal of Human Resource Management 5 (2), pp. 301-314. 


\section{About the Authors}

Gloria H. W. Liu is a PhD student of Department of Information Management at National Central University, Taiwan. Her research interests are in the areas of knowledge management, intellectual capital, organizational routines and qualitative research.

Dr. Eric T. G. Wang is Chair Professor of Department of Information Management at National Central University, Taiwan (R.O.C.). $\mathrm{He}$ received the Ph.D. degree in Business Administration, specialized in computer \& information systems, from the William E. Simon Graduate School of Business
Administration, University of Rochester. His research interests include electronic commerce, supply chain management, outsourcing, organizational economics, and organizational impact of information technology. His research has appeared in Journal of Management Information Management, Information Systems Research, Management Science, Decision Sciences, Decision Support Systems, Information Systems Journal, Information \& Management, European Journal of Information Systems, Omega, European Journal of Operational Research and others. 